\title{
СИНДРОМ СУСАК. КЛИНИЧЕСКОЕ НАБЛЮДЕНИЕ
}

\author{
*Р.Г.Есин ${ }^{1}$, Э.И.Гисматуллина ${ }^{2}$, Н.В.Токарева ${ }^{2}$ \\ ${ }^{1}$ Казанская государственная медицинская академия, Казань, Россия \\ ${ }^{2}$ Республиканская клиническая больница №2, Казань, Россия
}

В статье обсуждаются клинические проявления синдрома Сусак: триада (энцефалопатия, потеря зрения из-за окклюзии ветвей артерии сетчатки и сенсоневральная тугоухость) и характерная МРТ-картина. Приводится клиническое наблюдение случая синдрома Сусак.

Ключевые слова: Синдром Сусак, диагностика, течение.

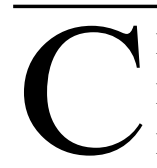

индром Сусак (СС) - редкое заболевание, предположительно аутоиммунной природы, в основе которого лежит микроангиопатия сосудов мозга, сетчатки и улитки, характеризующееся классической триадой: энцефалопатией, вторичной потерей зрения вследствие окклюзии ветвей артерии сетчатки и сенсоневральной тугоухостью [1]. Заболевание впервые описал в 1979 году американский нейроофтальмолог John O. Susac после наблюдения двух молодых женщин с изменениями личности, потерей слуха и нарушениями зрения. Он предположил иммуноопосредованный характер заболевания и предложил название "микроангиопатия" [2].

СС рассматривается как иммуноопосредованная эндотелиопатия неизвестной этиологии, при котором продуцируются аутоантитела, направленные против эндотелиальных клеток мелких сосудов. Отек, повреждение эндотелиальных клеток ведут к нарушению проходимости сосудов [3-6].

Биопсия мозга при СС выявляет инфаркты диаметром около 500 мкм в коре и белом веществе и минимальные периваскулярные воспалительные изменения [5]. Не обнаруживаются признаки фибриноидного некроза, некротизирующего васкулита или амилоидной ангиопатии [4,5].

Чаще СС возникает у молодых женщин в возрасте 18-40 лет, но описаны и случаи заболевания мужчин $[7,8]$. Семейные случаи заболевания не описаны. Энцефалопатия может манифестировать психиатрическими симптомами, спутанностью сознания, потерей памяти, снижением когнитивных функций. Окклюзия ветвей артерии сетчатки может развиться до, во время или *e-mail: radyesin@gmail.com после энцефалопатии, и служить причиной скотомы или фотопсий. Мигренозная головная боль часто предшествует остальным симптомам, и ассоциация ее со зрительными симптомами может вводить в заблуждение. Потеря слуха может быть трудна для оценки при тяжелой энцефалопатии. Зачастую в первую очередь страдает восприятие низких тонов, что свидетельствует об инфаркте вершины улитки $[4,9,10]$.

Диагностика СС требует высочайшей настороженности в отношении этого заболевания, так как полная триада симптомов при первом визите к врачу встречается редко. Пациенты с энцефалопатией могут не замечать проблемы со слухом или зрением [7]. МРТ головного мозга, исследование глазного дна через расширенный зрачок и флюоресцентная ангиография сетчатки - наиболее полезные исследования [1].

МРТ головного мозга выявляет множественные небольшие гиперинтенсивные Т2-очаги и накапливающие контраст очаги в сером и белом веществе мозжечка и подкорковых структурах [4,9]. Очаги выявляются в мозолистом теле, внутренней капсуле, перивентрикулярном белом веществе, стволе мозга, мозжечке, ножках мозга и мозжечка, базальных ганглиях и таламусе [5,6,7,9,10,11]. Обычно очаги имеют небольшой размер 3-7 мм. Мозолистое тело поражается у 88-100\% пациентов. Каллозальные поражения, возникающие при острой энцефалопатии, имеют центральную локализацию и напоминают комья снега (рис. 1, 2). Часто выявляются очаги, накапливающие контраст, в базальных ганглиях, таламусе, стволе мозга, мозжечке. Серое вещество поражается у 70\% пациентов. При обширном поражении лентикулостриарных арте- 
рий, могут встречаться очаги, напоминающие "гигантские лакуны". Иногда отмечается накопление контраста в мягкой мозговой оболочке. Артериография обычно нормальна, так как размер пораженных артериол настолько мал, что не заметен при ангиографии [7]. МРТ-находки могут способствовать оши- бочной диагностике рассеянного склероза или острого рассеянного энцефаломиелита, морфология и центральная локализация острых каллозальных поражений и их эволюция в Т1-гиподенсивные "дыры" характерно для СС и не типично для рассеянного склероза, при котором они меньше и локализуются в

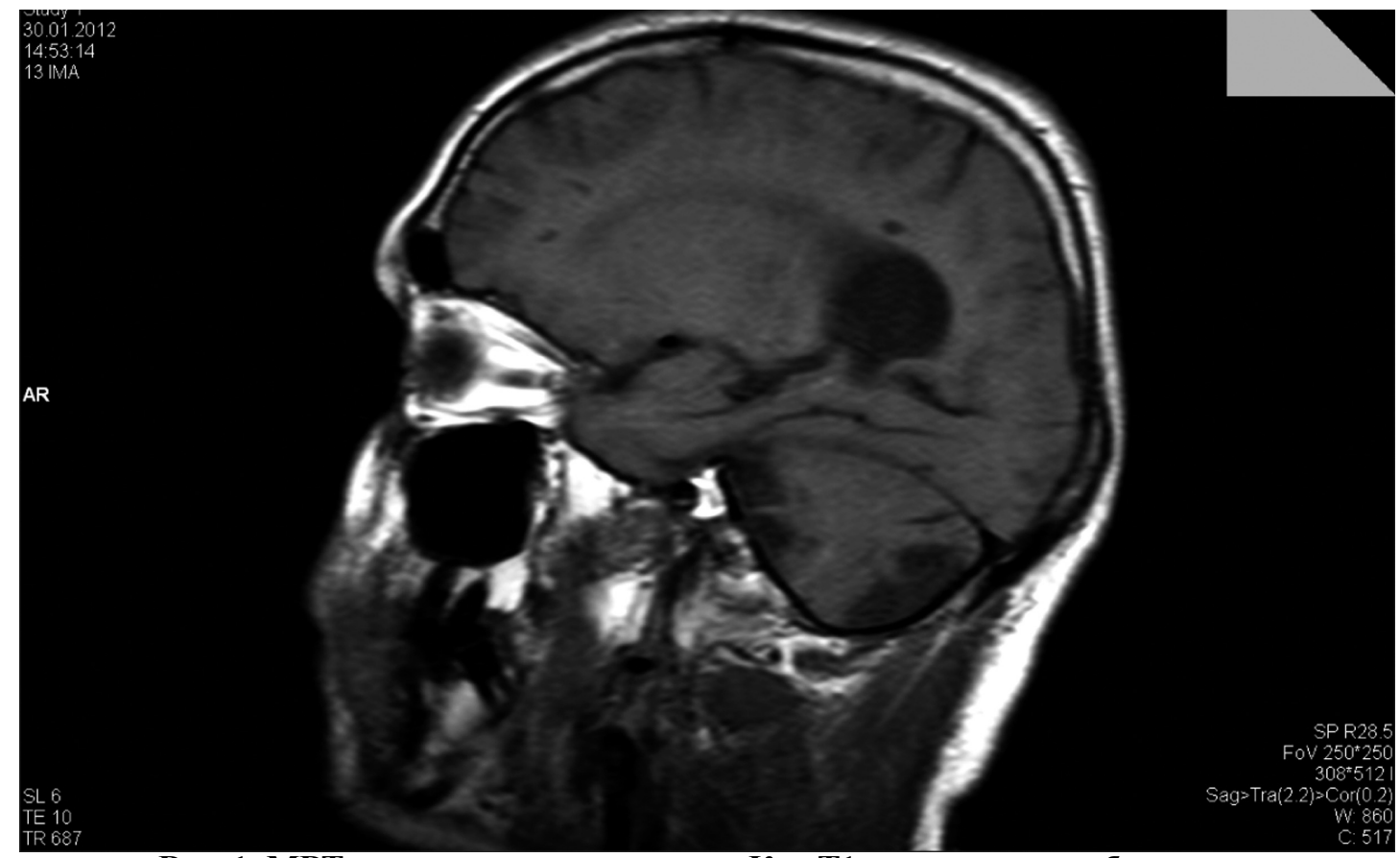

Рис. 1. МРТ головного мозга пациента К. в Т1-взвешенном изображении: гипоинтенсинвные очаги в мозолистом теле ("каллозальные дыры") и мозжечке.

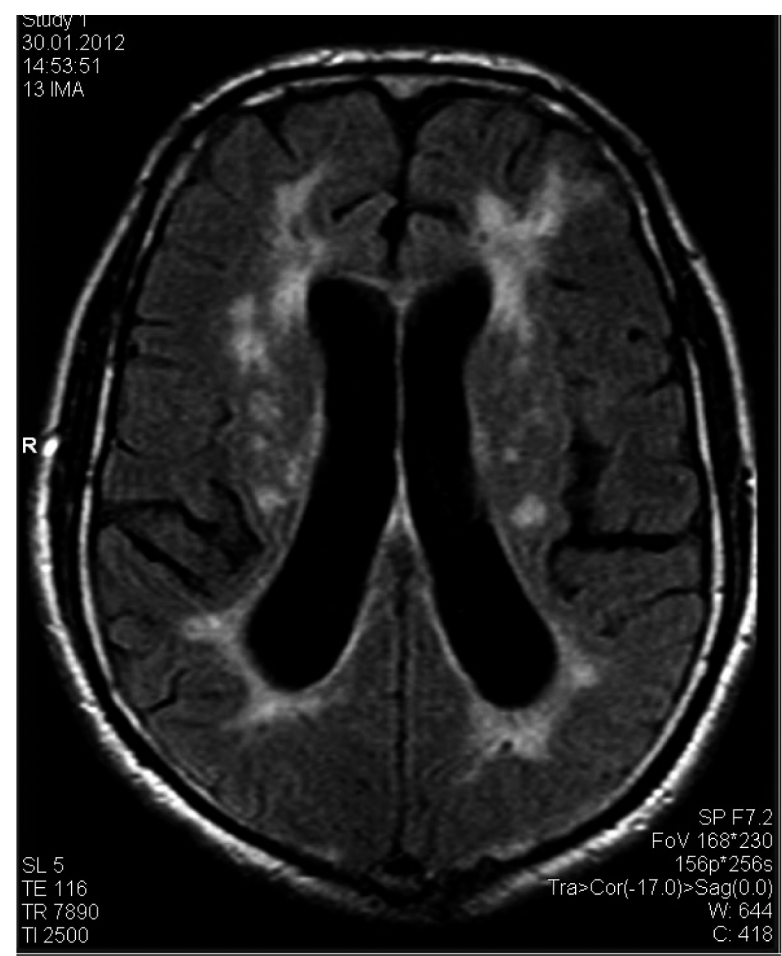

Рис. 2. МРТ головного мозга пациента К. в режиме FLAIR: множественные гиперинтенсивные очаги в белом веществе полушарий. каллозально-септальном пространстве [7].

Осмотр глазного дна через расширенный зрачок и флюоресцентная ангиография сетчатки могут обнаружить инфаркты сетчатки и окклюзию ветвей артерии сетчатки, снижение слуха подтверждается аудиометрией $[1,4,10]$.

Исследование цереброспинальной жидкости при острой энцефалопатии обычно обнаруживает легкий лимфоцитарный плеоцитоз. Содержание белка обычно более 100 мг/дл, что нетипично для РС (1).

Описаны три типа течения CC: моноцикличный, полицикличный и хронический. У большинства пациентов с симптомами энцефалопатии имеет место моноцикличный тип течения, при котором наступает спонтанная ремиссия через 1-2 года и не более обострения не повторяются. Полицикличный тип течения характеризуется периодами ремиссии и персистенцией в течение многих лет. Хронический тип течения имеет различную выраженность тяжести симп- 
томов без ремиссий. Существующие наблюдения показывают, что лица с преимущественно энцефалопатическими симптомами чаще имеют моноциклическое течение, а те, у кого имеет место окклюзия ветвей артерии сетчатки и снижение слуха, более часто имеют длительное полициклическое течение [12,13].

В настоящее время для лечения СС предлагается интенсивная иммуносупрессивная терапия: кортикостероиды (преднизолон, пульстерапия метилпреднизолоном), внутривенный иммуноглобулин, цитостатики (циклофосфамид, азатиоприн). Чем раньше начато лечение, тем оно эффективнее. Антикоагулянты не доказали свою эффективность в лечении данного заболевания [3,4,5,9,10,11,14].

\section{Приводим собственное наблюдение.}

Пациент К. 45 лет врач, имеет двоих детей. Анамнез собран со слов сестры и по предоставленной медицинской документации, так как при поступлении контакт с пациентом был затруднен из-за выраженного нарушения слуха (до анакузии справа) и психоогранического синдрома.

Наследственных заболеваний в семье не отмечалось. Длительное время страдал артериальной гипертензией, препараты, назначенные терапевтом, не принимал, считая их неэффективными. 1 июня 2009 года был доставлен бригадой скорой помощи в неврологический стационар одной из клиник Казани с жалобами на головную боль, шаткость при ходьбе, общую слабость, возникшие остро на фоне подъема АД. Осмотрен неврологом. МРТ головного мозга: резидуальные очаги инфарктов в левой лобной доле и правом полушарии мозжечка; очаговая сосудистая энцефалопатия; свежих очагов кровоизлияния и ишемии не выявлено. МРА головного мозга: виллизиев круг не замкнут, неровность контуров обеих 3МА, гипоплазия правой позвоночной артерии. Данных за ОНМК не выявлено, в госпитализации отказано.

В дальнейшем появилось эпизодическое непродолжительное онемение в левых конечностях, лечился амбулаторно. В июне 2010 года эпизод непродолжительной слабости в левой ноге (при ходьбе подволакивал ногу) и асимме- трии лица. Через неделю после данного эпизода, 25.06.2010г. на фоне подъема АД до 200/150 мм рт.ст. возникло онемение в левых конечностях. Вызвана бригада скорой помощи, доставлен в ту же неврологическиую клинику Казани. МРТ+MРА головного мозга: лакунарные очаги острой ишемии в правой и левой лобной долях, в стволе справа и выраженные очагово-дистрофические изменения в головном мозге на фоне стеноза, сужения просвета обеих СМА; мегадолихобазилярная аномалия с аневризматическим расширением основной артерии и компрессией ствола мозга. Диагноз: ишемический инсульт (лакунарный) в бассейне правой СМА в форме левосторонней гемигипестезии, легкого левостороннего гемипареза. При выписке сохранялся легкий левосторонний монопарез в руке, дисметрия слева.

12 сентября 2010 года доставлен в неотложную неврологию другой клиники Казани изза слабости в правых конечностях, нарушение речи. Глазное дно: ДЗН розовые, контуры дисков четкие, артерии сужены, склерозированы, вены умеренно расширены. Диагноз: "Повторный ишемический инсульт в бассейне левой СМА в форме элементов моторной афазии, умеренного правостороннего гемипареза, общемозгового синдрома". При выписке сохранялся легкий правосторонний гемипарез, умеренная атаксия и дисметрия справа и слева. Установлена II группа инвалидности.

2 мая 2011 года доставлен в то же отделение неотложной неврологии с жалобами на шаткость при ходьбе, головокружение. МРТ+МРА головного мозга: "в правой гемисфере мозжечка и правой ножке мозжечка очаги острой ишемии размерами $3,1 \times 1,7 \times 1,6 \mathrm{~cm}$ и $2,3 \times 1.3 \times 1,6 \mathrm{~cm}$ соответственно. В белом веществе обеих гемисфер большого мозга, мозжечка, мозолистом теле, веществе моста множественные очаги дистрофического и постишемического характера. Большая аневризма основной артерии". Глазное дно: ДЗН бледно-розовые, деколорация височных половин, артерии сужены, склерозированы, вены расширены, Симптом Салюса II. Диагноз: повторный ишемический инсульт в ВББ в форме вестибулопатии, мозжечковой симптоматики. 
После выписки отметил ухудшение слуха на правое ухо, появилось нарушение поведения (стал агрессивен, плаксив), наблюдался у психотерапевта. Продолжал работать, с обязанностями справлялся плохо, был вынужден взять отпуск.

30 января 2012 года доставлен в сосудистый центр республиканской клинической больницы №2 в сопровождении сестры с жалобами на выраженную шаткость при ходьбе, рвоту, возникшие на фоне подъема АД до 200/100 мм рт. ст. В неврологическом статусе при поступлении: диплопия, нистагм среднеразмашистый влево, анакузия справа, гипоакузия слева, в пробе Ромберга отклоняется влево. Позднее присоединился насильственный смех. МРТ+МРА головного мозга: множественные мелкие очаги острого ишемического инфаркта общим размером 36х43×24 мм; мультиинфарктная энцефалопатия; аневризма базилярной артерии размером 27×21×33 мм. Глазное дно: ДЗН - границы четкие, височная деколорация, артерии узкие, венулы расширены, Салюс II. Частичная атрофия зрительных нервов. Гипертоническая ретинопатия I степени. ЛОР: хроническая двусторонняя сенсоневральная тугоухость. Психиатр: органическое поражение головного мозга сосудистого генеза (осложненное психотравмой) с полиморфными неврологическими и психическими проявлениями, наряду с легкими когнитивными и эмоциональными изменениями. Иммунолог: имеется повышение относительного и абсолютного содержания NK-T лимфоцитов, которое в совокупности с избыточным накоплением CD4+ T-клеток памяти/эффекторов (CD4+ CD62L-), может косвенно свидетельствовать об иммунозависимом Т-клеточном повреждении нервной ткани. Нейрохирург: гигантская неразорвавшаяся аневризма базилярной артерии. Рекомендуется дообследование в условиях нейрохирургического отделения (в плановом порядке). Диагноз: Острый ишемический инфаркт левого полушария мозжечка. Мультиинфарктная энцефалопатия (синдром Susac).

От предложенной иммуносупрессивной терапии пациент и его доверенное лицо отказа- лись. Дальнейшая судьба пациента не известна.

Обсуждение. Настоящее клиническое наблюдение представляется важным с той точки зрения, что врачи неотложных неврологических клиник (сосудистых центров) часто не рассматривают инсульт как стадию развития основного сосудистого, кардиального, гематологического или иного заболевания, одним из проявлений которого явилось нарушение церебрального кровотока. Инсульт рассматривается только как инсульт "per se", что является причиной диагностических и терапевтических ошибок.

В данном клиническом наблюдении при первом обращении пациента на МРТ были обнаружены множественные перенесенные церебральные и мозжечковые инфаркты, что должно было послужить поводом для вопроса "какое заболевание вызвало множественные инфаркты мозга в возрасте 42 лет и ранее?". Для гипертонической болезни такую МРТкартину типичной признать не возможно. Тот же наблюдалось и при госпитализации в отделение ургентной неврологии другой клиники.

У описанного пациента обращало внимание множественность поражения головного мозга и мозжечка, зрительные и слуховые расстройства при отсутствии явного заболевания, способного объяснить выявленные факты. Дифференциальная диагностика проводилась между церебральной аутосомно-доминантной артериопатией с субкортикальными инфарктами и лейкоэнцефалопатией (CADASIL) и изолированным церебральным васкулитом. Изолированный церебральный васкулит - достаточно редкое заболевание, требующее для своего подтверждения биопсии мозга или его оболочек [15]. Фактически СС является вариантом изолированного церебрального васкулита, имеющего большие бассейны поражения, чем иные формы и включающего различные варианты прогрессирования. В описанном нами клиническом наблюдении в пользу СС свидетельствовали: характерная клиническая и МРТ картины, признаки аутоиммунной агрессии, выявленные иммунофенотипированием лейкоцитов, отсутствие иного объяснения клинической картины. 


\section{ЛИТЕРАТУРА}

1. Do TH, Fisch C, Evoy F. Susac syndrome: report of four cases and review of the literature. AJNR Am J Neuroradiol. 2004 Mar;25(3):382-388.

2. Susac JO, Hardman JM, Selhorst JB. Microangiopathy of the brain and retina. Neurology 1979;29:313-316.

3. Ayache D, Plouin GI, Bakouche P, et al. Microangiopathy of the inner ear, retina, and brain (Susac syndrome): report of a case. Arch Otolaryngol Head Neck Surg 2000;126:82-84.

4. Petty GW, Engel AG, Younge BR, et al. Retinocochleocerebral vasculopathy. Medicine (Baltimore) 1998;77:12-40.

5. Papo T, Biousse V, Lehoang P, et al. Susac syndrome. Medicine (Baltimore) 1998;77:3-11.

6. Petty GW, Matteson EL, Younge BR, et al. Recurrence of Susac syndrome (retinocochleocerebral vasculopathy) after remission of 18 years. Mayo Clin Proc 2001;76:958-960.

7. Susac JO, Murtagh FR, Egan RA, et al. MRI findings in Susac's syndrome. Neurology2003;61:1783 1787

8. Murata Y, Inada K, Negi A. Susac syndrome. Am J Ophthalmol 2000;129:682 -684

9. O'Halloran HS, Pearson PA, Lee WB, et al. Microangiopathy of the brain, retina, and cochlea
(Susac syndrome): a report of five cases and a review of the literature. Ophthalmology 1998;105:10381044.

10. Monteiro ML, Swanson RA, Coppeto JR, et al. A microangiopathic syndrome of encephalopathy, hearing loss, and retinal arteriolar occlusions. Neurology 1985;35:1113-1121.

11. Susac JO. Susac's syndrome: the triad of microangiopathy of the brain and retina with hearing loss in young women. Neurology 1994;44:591-593.

12. El Chehab H, Le Corre A, Ract-Madoux G, et.al. Susac syndrome: variable onset modes and disease courses: two case reports. J Fr Ophtalmol. 2010 Oct;33(8):575.e1-7. Epub 2010 Sep 16.

13. C. Dielman, G. Laureys, A. Meurs et al. Susac syndrome: a case report and PET imaging findings. Acta Neurol. Belg. 2009, 109, 226-230.

14. Nicolle MW, Mclachlan RS. Microangiopathy with retinopathy, encephalopathy, and deafness (RED-M) and systemic features. Semin Arthritis Rheum 1991;21:123-128.

15. Scolding NJ, Wilson $H$, Hohlfeld $R$ et al. Cerebral vasculitis. In: European Handbook of Neurological Management: Volume 1, 2nd Edition/ Edited by N. E. Gilhus, M. P. Barnes and M. Brainin.- 2011. Blackwell Publishing Ltd.: 485-489

\title{
SUMMARY
}

\section{SUSAC SYNDROME. CASE REPORT}

\author{
R.G.Esin', E.I.Gismatullina ${ }^{2}$, N.V.Tokareva ${ }^{2}$ \\ ${ }^{1}$ Kazan State Medical Academy, Kazan, Russia \\ ${ }^{2}$ Republican Clinical Hospital №2, Kazan, Russia
}

The article discusses clinical manifestations of Susac syndrome: triad, including encephalopathy, secondary loss of vision due to retinal arteriolar branch occlusion, sensorineural hearing loss; typical MRI findings. Clinical observation of the case Susac syndrome is given.

Key words: Susac syndrome, diagnostics, clinical course. 


\title{
XÜLASə
}

\section{SUSAK SINDDOMU. KLINIIK HADISO}

\author{
R.Q.Yesin ${ }^{1}$, E.İ.Qismatullina², N.V.Tokareva² \\ ${ }^{1}$ Kazan dövlat tibb akademiyası, Kazan, Rusiyal; \\ ${ }^{2} 2$ saylı Respublika Klinik Xəstəxanası, Kazan, Rusiya
}

Təqdim edilmiş məqalədə Susak sindromunun kliniki əlamətləri müzakirə edilir: triada (ensefalopatiya, tor qişanın arteriyalarının şaxələrinin okklüziyası nəticəsində görmənin itirilməsi və sensonevral karlıq) və xarakter maqnit rezonans tomoqrafiya mənzərəsi. Susak sindromunun klinik müşahidəsi təqdim edilir.

Açar sözlər: Susak sindromu, diaqnostikası, gedişi.

Redaksiyaya daxil olub: 17.09.2013

Çapa tövsiya olunub: 09.10.2013

Rəyçi: R.K.Şiraliyeva, t.e.d., prof. 